\title{
The use of importance-performance analysis (IPA) in evaluating key attributes of Vietnam's universities
}

\author{
Nguyen Thi Kim Chi ${ }^{1{ }^{1} 凶}$, Nguyen Van Tuan ${ }^{2}$, and Nguyen Minh Dat $^{3}$ \\ ${ }^{1}$ Hanoi University of Business and Technology, Hà Nội 100000, Vietnam (Email: chikkte@gmail.com) \\ ${ }^{2}$ Hanoi Multidisciplinary Vocational School, Hà Nội 100000, Vietnam (Email: ydc.edu.vn@gmail.com) \\ ${ }^{3}$ Ho Chi Minh City University of Law, Hồ Chí Minh 7000oo, Vietnam (Email: Joe.nguyen1405@gmail.com)
}

\section{ABSTRACT}

Original Article

PII: S232247701900003-9

In Vietnam, administrators from tertiary education institutions consider education as a service, recognizing the importance of providing good training services to meet students' needs and to attract student's enrollment. The author of this research uses the IPA (importance-performance analysis) model to evaluate key university attribute criteria from the perspective of high school students who are subjected to education service and would be university students. The findings of this study are expected to help education managers in identifying strengths and weaknesses of universities in order to seek solutions to better meeting the needs of potential students.
Rec. 22 May, 2019

Acc. 20 July, 2019

Pub. 25 September, 2019

Keywords

Importance-Performance

Analysis (IPA),

College choice

School choice,

Higher education

\section{INTRODUCTION}

The IPA (Importance-Performance Analysis) model was developed by Martilla and James (1977). The IPAbased research results help businesses identify the importance of service targets, strengths and weaknesses of products/services in the market. The IPA model is implemented by comparison of two criteria that shape clients' choice, namely the importance of attributes and the level of performance of quality attributes. This comparison is of great necessity as key quality attributes are regarded as a relative reflection of their value to customer's perceptions; and the level of attainment of quality attributes would be reconciled to their importance (Slack, 1991). Via the comparison and contrast, customers' consuming behavior will be defined. If a quality attribute is low, it will reflect less impact on customers' overall perception to the quality of service/product. Conversely, if a quality attribute is high, it will have a great impact on customers' perceptions (Barsky, 1995).

When evaluating the importance of quality attributes, researchers identify through the following steps: (1) group discussions between experts and managers to fully list the attributes as a basis for evaluations; (2) design of a questionnaire to collect information of customers who assess the importance of each attribute and its performance; (3) processing of data and use of the mean to calculate and compare the importance and level of performance of each quality attribute.

The IPA model has been used extensively in such sectors as tourism, education, banking etc. For the education, the IPA has been used to determine attributes of universities in students' choice in the selection of a tertiary institution.

\section{Overview of researches and model proposed for Vietnam}

- Model of Joseph and Joseph (2000)

Joseph and Joseph (2000) were the first to apply the IPA model to determine the importance of each university attribute to student's choice criteria in selection of tertiary institution. The authors conducted two studies to examine factors that influence international students' decision on selection of tertiary institution: the first, done in 1998 in New Zealand, built 17 scales and surveyed 300 high school students. The second done in 2000, in which the authors adopted their New Zealand research and further developed a similar research in Indonesia. The study subjects are 200 high school students in central Jakarta. The difference between the two studies is the division of 17 scales into five elements. The difference is that the general factor in the 1998 study is renamed to the academic and career information in the 2000 research. 


\section{- Model of Wagner et al. (2009)}

Karld Wagner and his associates conducted a research by in Malaysia in 2009, examining 162 students enrolling in university preparatory classes or and new school leavers. As the educational contexts in Malaysia and Indonesia are similar, Wanger et al. (2009) adopted the research findings by Joseph and Joseph (1998) and adapted them to their study aims. Thus, the model of Wagner et al. (2009) split the general factors into two elements, namely Information on Institutions and Significant People. The results of the three models are summarized in table 1.

\section{- Model of Sia (2010)}

The subjects of the study were high school students attending preparatory university programs at Malaysian schools and school leavers with national graduation exam (SPM/MCE) certificates, or certificates on completion of university foundation programs (including two groups of A-level and a group of university entrance candidates); i.e. the students have real intentions of choosing a university at the time of the survey.

The model was then adopted and adapted from three models of Chapman (1981), Joseph and Joseph (1998 and 2000) and Wagner et al. (2009). The common point of these studies is the use of IPA in developing criteria and evaluation of university attributes from the perspective of high school students-potential university students. In this study, the author also inherits the above-mentioned studies and selects five attributes of a university, including: cost, curriculum, value of education, information on career and academic programs.

Table 1. Comparison of Research Findings by Joseph and Joseph (1998, 2000) and Wanger et al. (2009)

\begin{tabular}{llll} 
Rank & Joseph and Joseph (1998) & Joseph and Joseph (2000) & Wanger et al. (2009) \\
\hline 1 & Value of education & Information on academic vocational programs & Tuition and financial aid policies \\
\hline 2 & Availability of programs & Facilities and resources & Value of education \\
\hline 3 & Cost & Cost & Curriculum \\
\hline 5 & Infrastructure and resources & Curriculum & Significant People \\
\hline 6 & General & Reputation & Facilities and resources \\
\hline
\end{tabular}

Author's analysis and syntheses

\section{METHODOLOGY}

Measurement of concepts: on application of by IPA, the author has designed a small-sized qualitative research. Five experts in the field of education and linguistics were invited to look at the relevance and precise interpretation of the contents of the scale which derived from the two studies by Joseph and Joseph (1998, 2000), Wagner et al. (2009); and Sia (2010). A quantitative questionnaire was designed on the basis of 5-point Likert scale that ranges students' assessments in accordance with the importance of attributes from 1 as not important to 5 as very important.

Data was collected through interviews with high school leavers from Hanoi who left high school and took the university entrance exam in 2016. With the help of teachers at local high schools, students' parents, leaders of high schools in Hanoi, data were collected both directly and indirectly. Data sampling was divided into two different phases. Phase 1 for a preliminary assessment of the reliability of the scales was conducted on a small group of around 100 samples. The collected results were 113 valid filled questionnaires for the preliminary assessment. In phase 2, the author sent out 500 questionnaires by developing a larger numbers of samples (relational network) for the collection of research data. The investigation period ran from mid-June 2016 to the end of October 2016, especially during the time when high school students completing their paperwork to register for university enrollment.

\section{RESULTS AND DISCUSSION}

\section{Description of the research sample}

As many as 361 out of 500 questionnaires were collected and valid for the research, with a response rate of $72 \%$. The samples were classified under the following criteria:

Gender. Of the 361 high school students surveyed, the proportion of men and women was fairly balanced, with $53 \%$ of women (191) and $47 \%$ of men (170).

Academic performance. The students with credit level of score account for the highest proportion of 208 students (58\%), followed by 114 (32\%) students with distinction of academic performance, 34 (9\%) with average score and 1\% weak students. 
Table 2. High school students' evaluation on university attributes*

\begin{tabular}{|c|c|c|c|c|}
\hline \multirow[b]{2}{*}{ Evaluation criteria } & \multirow[b]{2}{*}{ Average } & \multirow[b]{2}{*}{ Deviation } & \multicolumn{2}{|c|}{ Reliability $95 \%$} \\
\hline & & & $\begin{array}{l}\text { Lower } \\
\text { bounds }\end{array}$ & $\begin{array}{l}\text { Upper } \\
\text { bounds }\end{array}$ \\
\hline Reasonable tuition policy & 3.687 & 1.064 & 3.577 & 3.797 \\
\hline Suitable cost of living & 3.856 & 1.138 & 3.738 & 3.974 \\
\hline Financial aid policies (scholarships, grants, concessional loans ...) & 4.139 & 1.018 & 4.033 & 4.244 \\
\hline Flexible tuition collection (tuition fees ...) & 3.803 & 1.102 & 3.689 & 3.917 \\
\hline Overall evaluation of tuition policy & 3.871 & 0.847 & 3.783 & 3.959 \\
\hline Courses/subjects with diversity of contents and structure for students' choice & 3.560 & 1.246 & 3.431 & 3.689 \\
\hline Flexible conditions for registering a study program/subject & 3.820 & 1.087 & 3.707 & 3.932 \\
\hline Intensive/advanced programs tailored to students' needs & 3.823 & 1.076 & 3.711 & 3.934 \\
\hline Programs with various practical content & 3.753 & 1.129 & 3.637 & 3.870 \\
\hline Flexibility in transferring of subjects/of major and specialization & 3.765 & 1.151 & 3.645 & 3.884 \\
\hline Overall evaluation of the curriculum & 3.744 & 0.912 & 3.650 & 3.838 \\
\hline Encouraging learning environment for students & 3.770 & 1.062 & 3.660 & 3.880 \\
\hline Resources to meet student learning needs & 3.953 & 1.062 & 3.843 & 4.063 \\
\hline Experienced, high quality faculty & 3.958 & 1.068 & 3.848 & 4.069 \\
\hline Overall evaluation of the infrastructure & 3.894 & 0.944 & 3.796 & 3.991 \\
\hline Institutions with academic reputation & 3.892 & 1.099 & 3.778 & 4.006 \\
\hline Institutions with prestige training programs & 3.715 & 1.061 & 3.605 & 3.825 \\
\hline Institutions with accredited academic programs/ highly-valued academic merit & 4.047 & 0.986 & 3.945 & 4.149 \\
\hline Overall evaluation of the value of education & 3.885 & 0.834 & 3.798 & 3.971 \\
\hline Institutions with information on career opportunities & 3.781 & 1.062 & 3.671 & 3.891 \\
\hline Institutions with information on the student's study/research field & 3.778 & 1.060 & 3.669 & 3.888 \\
\hline Institutions with information on post graduate or higher education courses & 3.795 & 1.042 & 3.687 & 3.903 \\
\hline Overall evaluation of the institution information & 3.785 & 0.929 & 3.689 & 3.881 \\
\hline
\end{tabular}

*Author's calculation with aid of SPSS

\section{Institution choice}

The rate of admission by entrance exam is five times higher than that by assessment of academic credentials with 304 students (84\%) enrolling by the entrance exam as compared with only 57 students (16\%) by academic credentials. Basically, the profile of survey respondents is quite suitable. The imbalanced rate of female to male is not significant (8\%). The percentage of pupils from urban and suburban areas is quite proportionate. The percentage of students with good academic performance is high (about 90\%). The proportion of students attending public schools is higher than that of non-state schools, which reflects a real current trend in high school education in Hanoi. It is also rational that the admission rate by exam is higher with $84 \%$ as students with good academic performance tend to challenge themselves in exams for an entry into prestige tertiary institutions.

\section{Results of evaluation of institution attributes \\ Choice criteria on tuition and financial aid}

policies. The results from the survey show that the tuition and financial aid policy gains a good grade of average of $3.871(\mathrm{SD}=0.847)$ on the 5-point scale. Particularly, the most appreciated criteria in selection of an institution is "financial aid policies such as scholarships, grants or concessional loans" (4.139); and the least "reasonable tuition policy" (3.687). This reveals a clear change and is well suited to the current context. School tuition policies have changed dramatically; the tuition gap between stateowned and non-state institutions has narrowed. At university, the amount of tuition depends on different training programs. Students are, therefore, more concerned about financial aid policies, scholarships and concessional loans in a hope to grasp an opportunity to lessen the financial burden on their families. 
Evaluation of the curriculum. For the curriculum factor, students gave a rather high overall score with an average of $3.744(\mathrm{SD}=0.912)$. In which, the most appreciated aspect is "the institution with an intensive/advanced curriculum tailored to students' needs" (3.823) and the lowest "the courses/subjects with diversity of contents and structure for students' choice" (3.560). It is an interesting finding as the respondents are students preparing for college. This shows that students are getting gradually matured in their choice of curriculum. They consider the need for intensive study and advanced research to acquire knowledge.

Assessments of facilities and resources. The results show that the score given by students with good academic performance is $3.894(\mathrm{SD}=0.944)$ on the 5-point scale. In which, the most appreciated aspect is the "high-quality, experienced teaching staff" (3.958) and the lowest "learning environment for students" (3.770). Students care more about the teaching staff with good and practical teaching experience. This reflects the fact that students evaluate the teachers as a decisive key.

Importance of value of education. The value of education of choice institutions was rated at a high level with an average score of 3,885 ( $\mathrm{SD}=0.834)$. Accordingly, the most appreciated aspect is "schools with accredited academic programs" (4.047) and the lowest is "the institutions with prestige training program" (3.715). The value of education of tertiary institutions manifests itself in many aspects. It is not only recognized by students, businesses/ organizations but also highly appreciated by other prestigious academic institutions.

Information on career and academic curriculum. Information about institution was rated at a quite high level with an average score of $3.785(S D=0.929)$ on a 5-point scale. The top score is for "institutions with information on post graduate or higher education courses" (3.795); and the lowest for "institutions with information on students' study/research filed" (3.778). This study directed at high school students who have enough conditions to choose which university to enroll so the information on higher education courses is most interested. According to qualitative research, students tend to think that institutions having master's degree training courses in cooperation with overseas institutions will take the advantage.

\section{CONCLUSION}

The research shows that high school students rank tertiary institutions' attributes in ascending order: the first is the material and resources in which the quality of teaching staff is most concerned. The second is the value of education of institutions on the basis of the recognition by prestigious academic rating agencies. The third is the tuition and financial aid policies, in which financial aid being the most important. The fourth is the information on career and academic curriculum due to students' interest in higher level of education information for their acquisition of knowledge. Last but not least is the emphasis on intensive/advanced academic programs. Basing on the findings, education managers, university administrators will be improving the quality of tertiary education services for better satisfaction of students' needs. In recognition of strengths, weaknesses of the institution, they will sort out an appropriate enrollment strategy. On the side of high school students, the study also indicates the "maturity" in their choice, reflects their confidence in profoundly evaluation of universities' attributes. However, this study bears certain limitations; that is it only reflects choice criteria of students with intention of selecting their upcoming tertiary institution. Therefore, a future research will focus on assessment of the perfectness of the IPA, including the evaluation of the degrees of implementing attributes.

\section{DECLARATIONS}

\section{Authors' Contributions}

All authors contributed equally to this work.

\section{Competing interests}

The authors declare that they have no competing interests.

\section{HEFERENCES}

Ajzen, I (1991). The theory of planned behavior. Organizational Behavior and Human Decision Processes. 50: 179-211. Google Scholar

Barsky, J.D (1995). World-Class Customer Satisfaction. Chicago, IL, Irwin Publishing. Google Scholar

Chapman D (1981). A model of student college choice. Journal of Higher Education, 52(5): 490-505. 
https://doi.org/10.1080/00221546.1981.11778120, Google Scholar

Joseph M and Joseph B (1998). Identify need of potential students in a tertiafy education for strategy development. Quality Assurance in Education, 6(2): 90-6. Google Scholar, https://doi.org/10.1108/09684889810205741

Joseph M and Joseph B (2000). Indonesian students' perceptions of choice criteria in the selection of a tertiary institution: strategic implications. The international Journal of Educational Management, 14(1): 40-44. Google Scholar, https://doi.org/10.1108/09513540010310396

Martilla JA, James JC. 1977. ImportancePerformance Analysis. J Mark; 41:77-9. https://doi.org/10.1177/002224297704100112 ， Google Scholar,

Sia J.K.M (2010). Institutional Factors Influencing Students' College Choice Decision in Malaysia: A Conceptual Framework. International Journal of Business and Social Science. 1(3): 53-58. Google Scholar

Slack.N (1991). Making Management Decisions. Prentice Hall. Google Scholar

Wagner, K and Fard PY (2009). Factors Influencing Malaysian Students' Intention to Study at a Higher Educational Institution. E-Leader Kuala Lumpur, Google Scholar 